\title{
Correction to: Polycyclic Aromatic Hydrocarbons, Mercury and Arsenic Content in Soils of Larsemann Hills, Pravda Coast and Fulmar Island, Eastern Antarctica
}

\author{
Ivan Alekseev ${ }^{1,2}$ (D) Evgeny Abakumov ${ }^{1}$ (B)
}

Received: 29 January 2021 / Accepted: 29 January 2021 / Published online: 6 February 2021

(c) Springer Science+Business Media, LLC, part of Springer Nature 2021

\section{Correction to: \\ Bulletin of Environmental Contamination and Toxicology https://doi.org/10.1007/s00128-020-03063-w}

The original version of the article unfortunately contained a mistake in Fig. 2, where numbers on the plot were not decoded.

The correct label of Fig. 2 is "Fig. 2. PAHs content (ng $\mathrm{g}^{-1}$ ) in soils of Larsemann Hills, Pravda coast and Fulmar Island. 1-2-methylnaphthalene; 2-Anthracene; 3Acenaphthene; 4-Acenaphthylene; 5-Benz(a)anthracene; 6-Benzo(a)pyrene; 7-Biphenyl; 8-Dibenzanthracene; 9-Naphthalene; 10-Pyrene; 11-Phenanthrene; 12Fluoranthene; 13-Fluorene; 14-Chrysene; 15-Benzo(A) fluoranthene; 16-Benzo[k]fluoranthene; 17-Benzo[ghi] perylene".

This has been corrected with this Erratum.

The original article can be found online at https://doi.org/10.1007/ s00128-020-03063-w.

Ivan Alekseev

alekseevivan95@gmail.com

1 Dept of Applied Ecology, Saint Petersburg State University, Saint Petersburg, Russia

2 Arctic and Antarctic Research Institute, Saint Petersburg, Russia 